\title{
The Compound U18666A Inhibits the Intoxication of Cells by Clostridioides difficile Toxins TcdA and TcdB
}

OPEN ACCESS

Edited by:

Meina Neumann-Schaal, German Collection of Microorganisms and Cell Cultures GmbH (DSMZ),

Germany

Reviewed by:

Harald Genth,

Hannover Medical School, Germany

Glen Carter,

The University of Melbourne, Australia

${ }^{*}$ Correspondence:

Panagiotis Papatheodorou

panagiotis.papatheodorou@

uni-ulm.de

†Present address:

Ebru Durgun,

Institute of Anatomy and Cell Biology,

Ulm University, Ulm, Germany

Tharani Thuraisingam,

Nuvisan GmbH, Neu-UIm, Germany

Alexander Witte,

Pfizer Manufacturing Deutschland

$\mathrm{GmbH}$, Freiburg, Germany

Shuo Song,

Central Laboratory, Shenzhen Samii

International Medical Center,

Shenzhen, China

Specialty section:

This article was submitted to Infectious Agents and Disease,

a section of the journal

Frontiers in Microbiology

Received: 28 September 2021 Accepted: 01 November 2021

Published: 29 November 2021

Citation:

Papatheodorou P, Kindig S, Badilla-Lobo A, Fischer S, Durgun E,

Thuraisingam $T$, Witte $A$, Song $S$,

Aktories K, Chaves-Olarte E, Rodriguez C and Barth H (2021) The

Compound U18666A Inhibits

the Intoxication of Cells by

Clostridioides difficile Toxins

$T c d A$ and $T c d B$.

Front. Microbiol. 12:784856.

doi: 10.3389/fmicb.2021.784856
Panagiotis Papatheodorou ${ }^{*}$, Selina Kindig ${ }^{1}$, Adriana Badilla-Lobo², Stephan Fischer ${ }^{1}$, Ebru Durgun ${ }^{1 \dagger}$, Tharani Thuraisingam ${ }^{1+}$, Alexander Witte ${ }^{3+}$, Shuo Song ${ }^{3 t}$, Klaus Aktories ${ }^{3}$, Esteban Chaves-Olarte ${ }^{2}$, César Rodríguez ${ }^{2}$ and Holger Barth ${ }^{1}$

${ }^{1}$ Institute of Pharmacology and Toxicology, Ulm University Medical Center, Ulm, Germany, ${ }^{2}$ Centro de Investigación en Enfermedades Tropicales and Facultad de Microbiología, Universidad de Costa Rica, San José, Costa Rica, ${ }^{3}$ Institute of Experimental and Clinical Pharmacology and Toxicology, Albert Ludwig University Freiburg, Freiburg, Germany

The intestinal pathogen Clostridioides (C.) difficile is a major cause of diarrhea both in hospitals and outpatient in industrialized countries. This bacterium produces two large exotoxins, toxin $A(T c d A)$ and toxin $B(T c d B)$, which are directly responsible for the onset of clinical symptoms of $C$. difficile-associated diseases (CDADs), such as antibiotics-associated diarrhea and the severe, life-threatening pseudomembranous colitis. Both toxins are multidomain proteins and taken up into host eukaryotic cells via receptor-mediated endocytosis. Within the cell, TcdA and TcdB inactivate Rho and/or Ras protein family members by glucosylation, which eventually results in cell death. The cytotoxic mode of action of the toxins is the main reason for the disease. Thus, compounds capable of inhibiting the cellular uptake and/or mode-of-action of both toxins are of high therapeutic interest. Recently, we found that the sterol regulatory element-binding protein 2 (SREBP-2) pathway, which regulates cholesterol content in membranes, is crucial for the intoxication of cells by TcdA and TcdB. Furthermore, it has been shown that membrane cholesterol is required for TcdA- as well as TcdB-mediated pore formation in endosomal membranes, which is a key step during the translocation of the glucosyltransferase domain of both toxins from endocytic vesicles into the cytosol of host cells. In the current study, we demonstrate that intoxication by TcdA and TcdB is diminished in cultured cells preincubated with the compound U18666A, an established inhibitor of cholesterol biosynthesis and/or intracellular transport. U18666A-pretreated cells were also less sensitive against $T c d A$ and $T c d B$ variants from the epidemic NAP1/027 C. difficile strain. Our study corroborates the crucial role of membrane cholesterol for cell entry of TcdA and TcdB, thus providing a valuable basis for the development of novel antitoxin strategies in the context of CDADs.

Keywords: bacterial toxin, toxin inhibitor, cholesterol biosynthesis, cholesterol transport, cholesterol

\section{INTRODUCTION}

Clostridioides difficile is a (nosocomial) pathogen of the human gut and the major cause of antibiotics-associated diarrhea and pseudomembranous colitis. This bacterium produces two exotoxins, toxin $\mathrm{A}(\mathrm{Tcd} A)$ and toxin $\mathrm{B}(\mathrm{TcdB})$, that belong to the family of the clostridial glucosylating toxins (CGTs), also referred to as large clostridial cytotoxins (LCCs). The onset of clinical symptoms after $C$. difficile infections (CDIs) is strictly dependent on the toxins' 
actions on target cells in the human gut (Kelly and LaMont, 2008; Aktories et al., 2017; Chandrasekaran and Lacy, 2017).

TcdA and TcdB are glucosylating toxins that specifically modify host cell target proteins by covalent attachment of a glucose moiety (Just et al., 1995). Both toxins utilize UDP-glucose for the mono-O-glucosylation of GTPases from the Rho and/or Ras family, which renders them inactive. Rho family members are master regulators of the actin cytoskeleton and numerous other cellular processes (Hall, 1994). Consequently, the intoxication of cultured mammalian cells with TcdA or TcdB leads amongst other effects to cell rounding due to the destruction of the actin cytoskeleton (Aktories and Just, 2005).

In order to reach their target proteins in the host cell cytosol, TcdA and TcdB need to enter cells via receptormediated, clathrin-dependent endocytosis (Papatheodorou et al., 2010). Both toxins are single-chain, multidomain toxins, which bind to host cell surface receptors via at least two independent, C-terminally located receptor-binding domains (Gerhard, 2017; Papatheodorou et al., 2018). After internalization of the toxin/receptor complexes, the $\mathrm{pH}$ of the endosomal lumen decreases, triggering membrane insertion and pore formation by a central region within TcdA and TcdB, denoted as translocation domain (TD) (Barth et al., 2001; Orrell et al., 2017). The glucosyltransferase domain (GTD) and the adjacent cysteine protease domain (CPD) are located at the $\mathrm{N}$-terminus of both toxins (Jank and Aktories, 2008). The TD enables the translocation of the GTD and CPD across the endosomal membrane. Eventually, binding of cytosolic inositol hexakisphosphate to CPD triggers autocatalytic cleavage and release of the GTD into the cytosol (Giesemann et al., 2008; Egerer et al., 2009).

Earlier findings indicated that membrane cholesterol is crucial for the generation of translocation pores formed by TcdA and TcdB in endosomal membranes (Giesemann et al., 2006). More recently, we were able to show that an active sterol regulatory element-binding protein 2 (SREBP-2) pathway, which regulates cholesterol content in membranes, is required for efficient uptake of TcdA and TcdB into target cells (Papatheodorou et al., 2019). In addition, we demonstrated that the cholesterollowering drug simvastatin significantly reduces the intoxication of mouse embryonic fibroblasts (MEF cells) with TcdB in vitro (Papatheodorou et al., 2019).

Prompted by these observations and based on the recognized inhibitory role of the amphipathic steroid U18666A (3$\beta$-[2-(diethylamino)ethoxy] androst-5-en-17-one) in cholesterol biosynthesis and/or intracellular transport (Cenedella, 2009), we investigated whether preincubation with the compound U18666A turns green monkey kidney epithelial cells (Vero), human cervix- (HeLa) and colon- ( $\mathrm{CaCo}-2)$ cancer cells less prone to intoxication by TcdB. Importantly, U18666A exhibited a protective effect against TcdB in the tested cell lines. In addition, U18666A also protected cells from TcdA as well as from TcdA and TcdB from the epidemic NAP1/027 C. difficile strain, which is of particular clinical relevance.

Overall, the results corroborate the crucial role of membrane cholesterol for cell entry of TcdA and TcdB and should pave the way for the development of novel pharmacological antitoxin strategies for the supportive therapy after CDI.

\section{MATERIALS AND METHODS}

\section{Cell Culture}

Minimum Essential Medium (MEM; Fisher Scientific GmbH, Schwerte, Germany; \#11524426) supplemented with 10\% fetal calf serum (FCS), 1\% sodium pyruvate, 1\% non-essential amino acids, and $1 \%$ penicillin/streptomycin was used for the cultivation of HeLa and Vero cells. CaCo-2 cells (CLS Cell Line Service GmbH, Eppelheim, Germany; \#300137) were cultivated in Dulbecco's Modified Eagle's Medium (DMEM; Fisher Scientific $\mathrm{GmbH}$, Schwerte, Germany; \#11594486) supplemented with $10 \%$ FCS, $1 \%$ sodium pyruvate, $1 \%$ non-essential amino acids, and $1 \%$ penicillin/streptomycin. Alternatively, HeLa cells were grown in DMEM (Fisher Scientific GmbH, Schwerte, Germany; \#13345364) supplemented with 10\% FCS and 1\% penicillin/streptomycin. Cells were maintained in the incubator under humidified conditions at $37^{\circ} \mathrm{C}$ and $5 \% \mathrm{CO}_{2}$.

\section{Toxins and Reagents}

TcdA from C. difficile VPI 10463 as well as TcdA and TcdB from a NAP1/027 strain were purified from $72 \mathrm{~h}$ culture supernatants using dialysis culture in Brain Heart Infusion broth as previously described (Lyerly et al., 1988; Pruitt et al., 2010). Toxin crosscontaminations were excluded by MALDI-TOF analysis. TcdB from C. difficile VPI 10463 was purified as described before (Just et al., 2008).

U18666A was ordered from Biomol (Hamburg, Germany; Cay10009085) or from Merck/Sigma-Aldrich (Darmstadt, Germany; U3633), dissolved in dimethyl sulfoxide (DMSO) to obtain a $20 \mathrm{mM}$ stock solution and aliquoted prior to storage at $-20^{\circ} \mathrm{C}$.

If not otherwise stated, incubation of cells with $C$. difficile toxins and/or the $\mathrm{U} 18666 \mathrm{~A}$ compound occurred at $37^{\circ} \mathrm{C}$.

\section{Microscopy}

The following microscopes were used for monitoring toxininduced cell rounding: Axiovert $40 \mathrm{CFL}$ microscope (Carl Zeiss Microscopy, Jena, Germany) equipped with a ProgRes C10 plus camera (Jenoptik, Jena, Germany); Leica DMil equipped with a Leica MC170 HD camera (Leica, Wetzlar, Germany); Primovert (Carl Zeiss Microscopy, Jena, Germany); Lionheart FX Automated Microscope (BioTek, Vermont, United States). Toxin-induced cell rounding was manually quantified in microscopic images and, optionally, facilitated by the Neuralab online tool (https://neuralab.de).

\section{Preparation of Whole-Cell Lysates and Immunoblotting}

Whole-cell lysates from cells growing in the wells from a 24well plate were generated directly in wells by removing the growth medium and resuspending cell monolayers in 2.5-fold pre-heated Laemmli buffer (typically $30 \mu \mathrm{l}$ per well). Lysate 
samples were heated at $95^{\circ} \mathrm{C}$ for $5 \mathrm{~min}$, prior to SDS-PAGE and Western blotting of lysate proteins onto a nitrocellulose membrane. For the immunodetection of non-glucosylated Rac1 and GAPDH, primary mouse anti-Rac1 (clone 102; BD Biosciences, Heidelberg, Germany; \#610651) and mouse antiGAPDH (G-9; Santa Cruz Biotechnology, Dallas, United States; sc-365062) antibodies were used, respectively. Horseradish peroxidase (HRP)-coupled mouse IgG kappa binding protein ( $\mathrm{m}$ IgGк BP-HRP; Santa Cruz Biotechnology, Dallas, United States; sc-516102) was used for developing antibody signals by the enhanced chemiluminescence (ECL) reaction.

\section{Measurement of Transepithelial Electrical Resistance}

The EVOMX apparatus equipped with the STX2 electrode (World Precision Instruments, Sarasota, United States) was used for measuring the transepithelial electrical resistance (TEER) of CaCo- 2 cells. At day $0,1.2 \times 10^{5}$ cells were seeded into 24 -well hanging cell culture inserts (Brand $\mathrm{GmbH}$, Wertheim, Germany; polyester membrane with pore size $0.4 \mu \mathrm{m}$ ) and incubated at $37^{\circ} \mathrm{C}$ until day 4 . Optionally, at day 3 , the U18666A compound was added basolaterally to the cells at a final concentration of $10 \mu \mathrm{M}$. Prior to TEER measurement at day 4, cell culture inserts were transferred into new wells containing only prewarmed medium and further incubated at $37^{\circ} \mathrm{C}$ until TEER values $(\sim 2,000 \Omega)$ were stabilized. Then, TcdB $(100 \mathrm{pM})$ was added apically to the cells and TEER measured every $30 \mathrm{~min}$ for up to $6 \mathrm{~h}$. TEER values were normalized to time point $0\left(\mathrm{t}_{0}\right.$, addition of the toxin), which was set to $100 \%$.

\section{Statistics}

Microsoft Excel (Student's) $t$-test was used for calculating the significance of differences between mean values. Resulting $p$-values were indicated by asterisks as follows: ${ }^{*} p<0.05$, ** $p<0.01,{ }^{* * *} p<0.001$.

\section{RESULTS}

\section{U18666A Inhibits the Intoxication of HeLa Cells by TcdB}

We initiated our study by using TcdB (derived from the historical C. difficile VPI 10463 strain) as representative for both C. difficile large glucosylating toxins and the human HeLa cervical carcinoma cell line as established model system for in vitro intoxication experiments. At first, we confirmed the biological activity of the prepared $\mathrm{TcdB}$ and identified an operable toxin concentration by analyzing cell rounding, which is a typical, specific, and well-established hallmark of intoxication of cells with TcdB or TcdA. Supplementary Figure 1A shows that TcdB (10 pM) directly added to HeLa cells lead to obvious cell rounding after $90 \mathrm{~min}$ of incubation and after $210 \mathrm{~min}$, almost all cells were round. In contrast, without toxin treatment, the cells maintained their flat morphology (Supplementary Figure 1A). Thus, $10 \mathrm{pM}$ of TcdB were used for the further experiments with HeLa cells.
U18666A is a pharmacological inhibitor of cholesterol biosynthesis and/or its intracellular transport (Cenedella, 2009). Therefore, a long-term incubation of cells with this compound is required to achieve a recognizable decrease in membrane cholesterol levels without causing cell toxicity. In this context, HeLa cells were incubated for $24 \mathrm{~h}$ with increasing concentrations of U18666A and their morphology was monitored microscopically for the same time period to identify the maximal tolerable concentration of U18666A. While HeLa cells tolerated U18666A concentrations up to $20 \mu \mathrm{M}$ after overnight treatment (Supplementary Figure 1B), $50 \mu \mathrm{M}$ U18666A was moderately toxic, as indicated by rounding up of a small proportion of cells, and $100 \mu \mathrm{M}$ U18666A lead to complete disruption of the cell layer and detachment of the cells. Therefore, overnight treatment with up to $20 \mu \mathrm{M}$ U18666A appears to be tolerable for HeLa cells. Nevertheless, we decided to limit the $\mathrm{U} 18666 \mathrm{~A}$ concentration at $10 \mu \mathrm{M}$ in subsequent experiments.

Next, we incubated HeLa cells with increasing concentrations of U18666A $(0,0.1,1$, and $10 \mu \mathrm{M})$ for $24 \mathrm{~h}$, followed by the direct addition of $10 \mathrm{pM}$ TcdB into the medium. Microscopic analysis of the cell morphology was performed at different time points after toxin application for up to $300 \mathrm{~min}$. Figure 1A shows representative images at time points 0 and $180 \mathrm{~min}$ after $\mathrm{TcdB}$ addition. In direct comparison, preincubation of cells with $10 \mu \mathrm{M}$ U18666A, but not with $0.1 \mu \mathrm{M}$ or $1 \mu \mathrm{M}$ U18666A, decreased the number of rounded cells in TcdB-treated cells (Figure 1A). Quantification of TcdB-induced cell rounding over time confirmed that HeLa cells pretreated with $10 \mu \mathrm{M}$ U18666A were less affected by the toxin $(\sim 25-30 \%$ reduced cell rounding after $180 \mathrm{~min}$ and $240 \mathrm{~min}$ ), when compared to mock-pretreated cells and cells pretreated with $1 \mu \mathrm{M}$ U18666A (Figure 1B).

\section{Incubation Time Impacts the U18666A-Mediated Inhibition of TcdB in HeLa Cells}

Since U18666A interferes with the cholesterol biosynthesis and/or intracellular transport, the incubation time with the compound correlates with the extent of decrease in membrane cholesterol levels. Thus, we aimed to analyze the consequences of various incubation periods during pretreatment of HeLa cells with the U18666A compound on the subsequent intoxication of the cells by TcdB. To this end, we pretreated HeLa cells with 10 $\mu \mathrm{M}$ U18666A for $0,2,4$, and $24 \mathrm{~h}$, and exchanged the U18666Acontaining medium with fresh medium including $10 \mathrm{pM}$ TcdB. We then analyzed microscopically and quantified TcdB-induced cell rounding over time up to $300 \mathrm{~min}$. In comparison to the cells without U18666A pretreatment, TcdB-induced cell rounding was inhibited only moderately $(\sim 10 \%$ reduced cell rounding at time point $180 \mathrm{~min}$ ) in cells pretreated for 2 and $4 \mathrm{~h}$, respectively, and most prominent inhibition ( $\sim 25 \%$ reduced cell rounding at time point $180 \mathrm{~min}$ ) was observed with a $24 \mathrm{~h}$ U18666 A pretreatment (Figure 2A). Thus, comparatively short incubation periods of cells with the U18666A compound correlate with less efficient protection against $\mathrm{TcdB}$ intoxication. Since $\mathrm{TcdB}$ intoxication took place after removal of the U18666A compound by medium exchange, direct inhibitory effects of U18666A on the activity of the toxin in the cell culture supernatant can be excluded. 
A

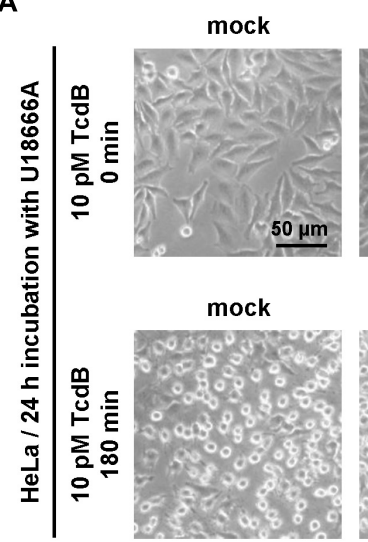

$0.1 \mu \mathrm{M} U 18666 \mathrm{~A}$

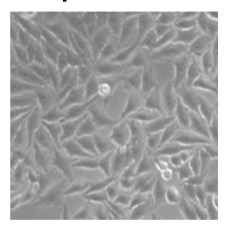

$0.1 \mu \mathrm{M} U 18666 \mathrm{~A}$

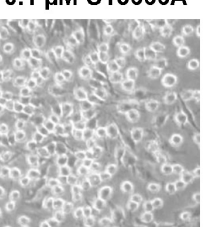

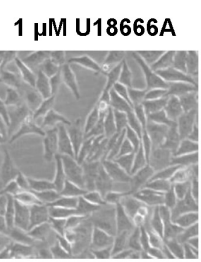

$1 \mu \mathrm{M} \mathrm{U} 18666 \mathrm{~A}$

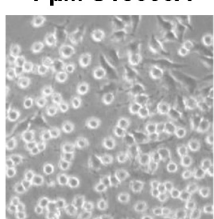

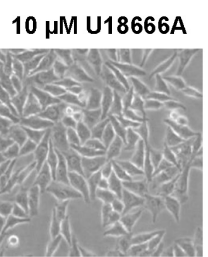

$10 \mu \mathrm{M} U 18666 \mathrm{~A}$

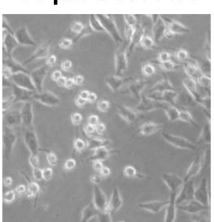

B

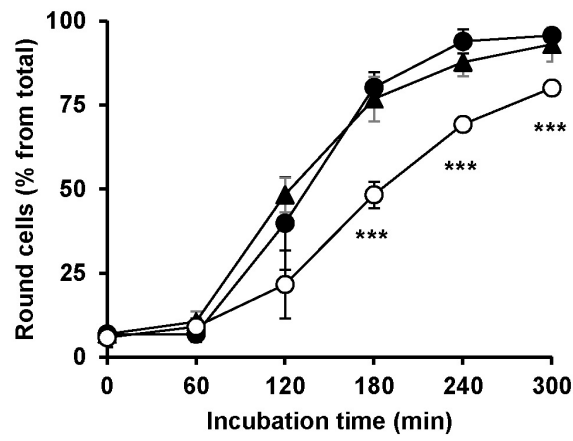

FIGURE 1 | Effect of U18666A on intoxication of HeLa cells by TcdB. (A) HeLa cells were pretreated for $24 \mathrm{~h}$ with increasing concentrations of U18666A as indicated or were left untreated (mock), prior to addition of $10 \mathrm{pM}$ TcdB. Microscopic images shown were taken after time point 0 min (upper row) and 180 min (lower row). (B) Quantification of the TcdB-induced cell rounding over time in mock-treated (black filled circles) and $24 \mathrm{~h}$ U18666A-pretreated HeLa cells (1 $\mu \mathrm{M}$, black filled triangles; $10 \mu \mathrm{M}$, white filled circles). Graph shows mean (percentage values of round cells) from three experiments performed in parallel in independent wells. Error bars represent \pm SD. Asterisks indicate statistical significance compared to control (mock-treated HeLa cells) with ${ }^{* \star *} p<0.001$.

A

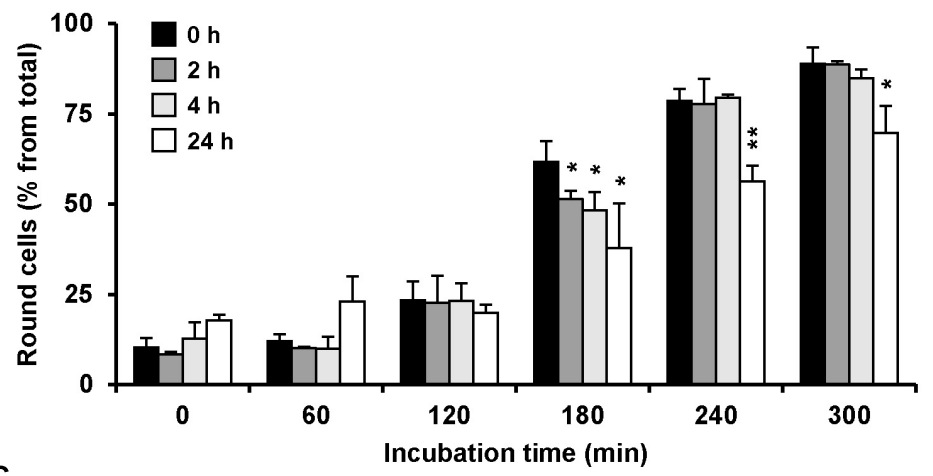

C

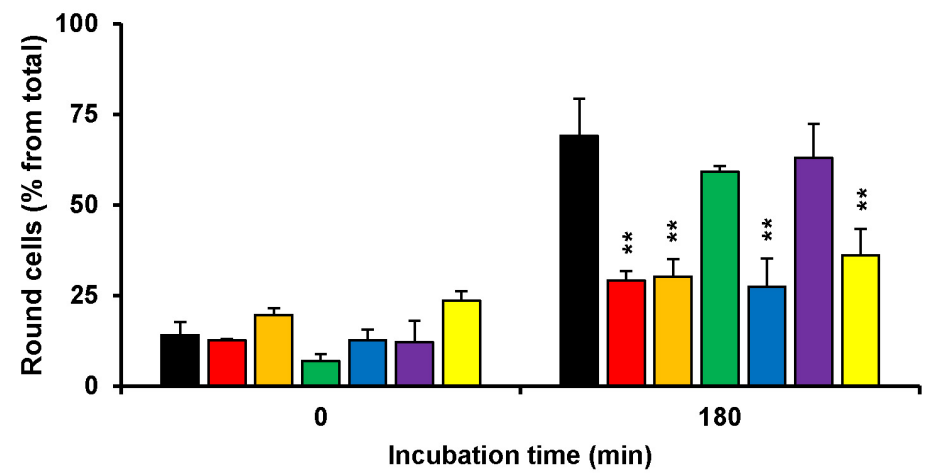

B
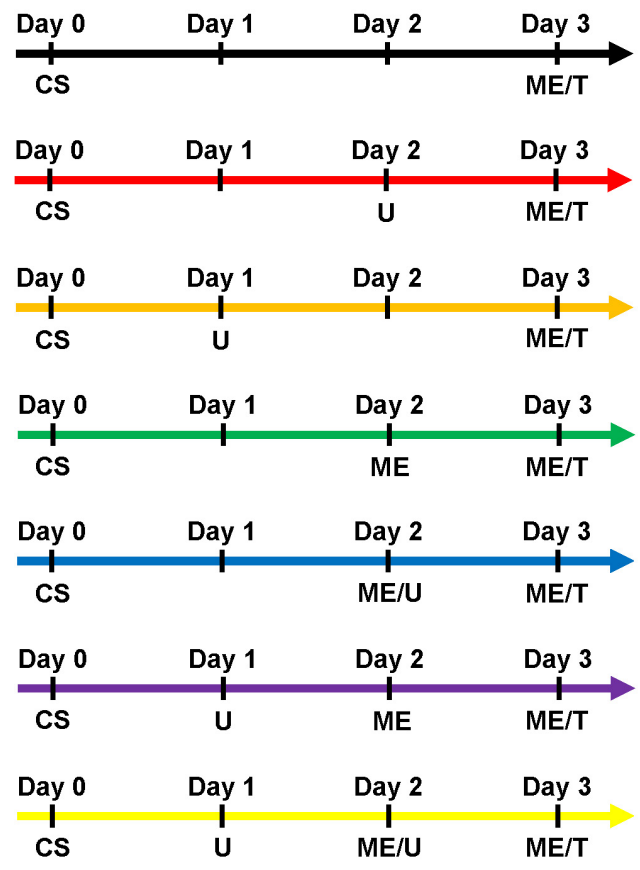

FIGURE 2 | Effect of U18666A preincubation conditions on the TcdB intoxicaton of HeLa cells. (A) HeLa cells were preincubated for $0 \mathrm{~h}$ (black bars), $2 \mathrm{~h}$ (dark gray bars), $4 \mathrm{~h}$ (light gray bars), and $24 \mathrm{~h}$ (white bars) with U18666A, followed by TcdB intoxication (10 pM) and microscopic analysis of TcdB-induced cell rounding over time. The bar chart shows mean percentages of round cells at the indicated incubation times after addition of the toxin. Error bars represent \pm SD. Asterisks indicate statistical significance at each time point compared to control (black bar) with ${ }^{*} p<0.05$ and ${ }^{* *} p<0.01$. (B,C) The various U18666A pretreatment- and TcdB-intoxication conditions shown in (C) are schematically depicted with different colors in (B). Cell seeding (CS) of HeLa cells at day 0 was followed by the addition of $10 \mu \mathrm{M}$ U18666A $(\mathrm{U})$ at day 1 (orange, purple and yellow) and/or at day 2 without (red) or with medium exchange (ME; blue, yellow) and TcdB intoxication (10 pM) by medium exchange (ME/T) at day 3. The bar chart in (C) shows the percentages of round cells at the indicated incubation times after addition of the toxin. Error bars represent \pm SD. Asterisks indicate statistical significance at each time point compared to control (black bar for red and orange bar; green bar for blue, purple and yellow bar) with ${ }^{* \star} p<0.01$. In all cases, data was obtained in three parallel experiments performed in independent wells. 
Next, we wanted to identify the best condition for the pretreatment of HeLa cells with U18666A, which are summarized schematically in Figure 2B, regarding the inhibition of TcdB intoxication in HeLa cells. For all conditions, cells were seeded into wells at day 0 and intoxicated at day 3 for $180 \mathrm{~min}$ with TcdB by exchanging the medium with fresh medium including $10 \mathrm{pM}$ TcdB. In the control condition (Figure 2B, black arrow), cells were not pretreated with the U18666A inhibitor and cell rounding occurred in $\sim 70 \%$ of the cells (Figure 2C, black bar). Direct addition of $10 \mu \mathrm{M}$ U18666A at day 2 (Figure 2B, red arrow; $24 \mathrm{~h}$ pretreatment) or day 1 (Figure $\mathbf{2 B}$, orange arrow; $48 \mathrm{~h}$ pretreatment), reduced cell rounding equally to $\sim 30 \%$ (Figure 2C, red vs. orange bar). Thus, $48 \mathrm{~h}$ pretreatment of $\mathrm{HeLa}$ cells with U18666A was not superior to the 24 h pretreatment, in terms of TcdB inhibition. We also tested the sequential addition of $10 \mu \mathrm{M}$ U18666A to cells, first by direct addition at day 1 and then by medium exchange at day 2 (Figure 2B, yellow arrow). Although cells were pretreated under this condition for a total of $48 \mathrm{~h}$ with the U18666A compound (but with U18666A renewal at day 2), TcdB inhibition was not superior to the $48 \mathrm{~h}$ pretreatment with U18666A without repeated application of the compound (Figure 2C, orange vs. yellow bar). Addition of $10 \mu \mathrm{M} \mathrm{U18666A}$ to cells at day 2 by medium exchange (Figure 2B, blue arrow) or by direct transfer into the wells (Figure 2B, red arrow), inhibited
TcdB-induced cell rounding to equal extents (Figure 2C, red vs. blue bar). Interestingly, when U18666A (10 $\mu \mathrm{M})$ was added to the cells at day 1 and removed again by medium exchange at day 2 (Figure 2B, purple arrow), TcdB-induced cell rounding was not inhibited and indistinguishable from the corresponding control without U18666A pretreatment at day 1 and medium exchange at day 2 (Figure 2C, green vs. purple bar). This finding suggests that membrane cholesterol levels recovered when U18666A was removed $24 \mathrm{~h}$ before toxin addition, either by cellular uptake from the medium or by biosynthesis.

\section{U18666A Confers Resistance Toward TcdB Intoxication in Vero Cells}

Next, the protective effect of U18666A against TcdB intoxication in a second cell line was investigated. African green monkey kidney (Vero) cells were used. Due to their flat morphology, Vero cells are a well-established model cell line for studying TcdB effects. Vero cells were pretreated for $24 \mathrm{~h}$ with increasing U18666A concentrations $(0,1,2,5,10 \mu \mathrm{M})$ and, subsequently, TcdB was added to the cells at a final concentration of 10 and $100 \mathrm{pM}$, respectively. TcdB-induced cell rounding was analyzed microscopically for up to $300 \mathrm{~min}(10 \mathrm{pM} \mathrm{TcdB})$ or $240 \mathrm{~min}$ (100 pM TcdB). Figures 3A,C show representative images of
A

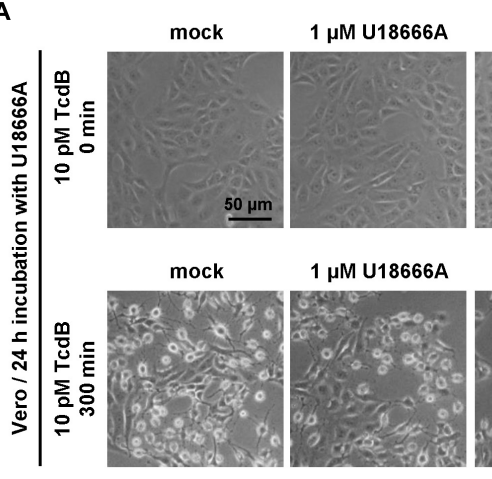

C

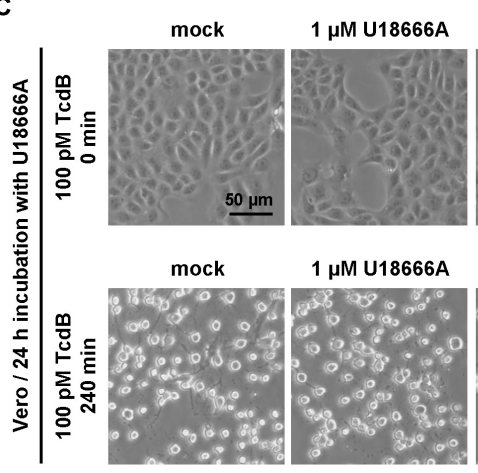

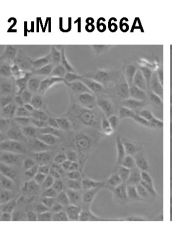

$2 \mu \mathrm{M}$ U18666A

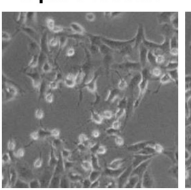

$2 \mu \mathrm{M}$ U18666A

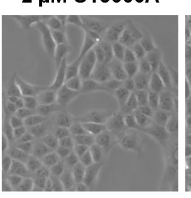

$2 \mu \mathrm{M} U 18666 \mathrm{~A}$

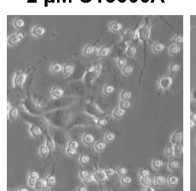

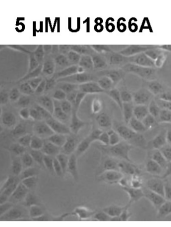

$5 \mu \mathrm{M}$ U18666A
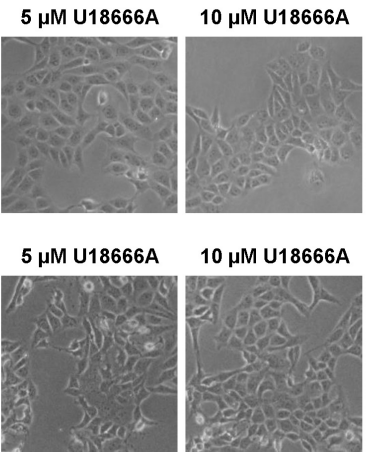

$5 \mu \mathrm{M}$ U18666A

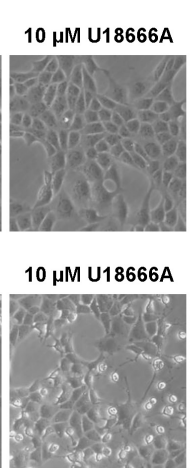

B

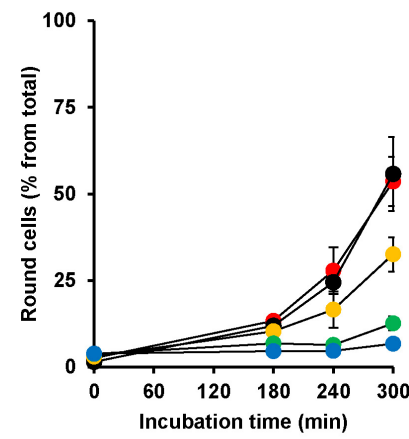

D

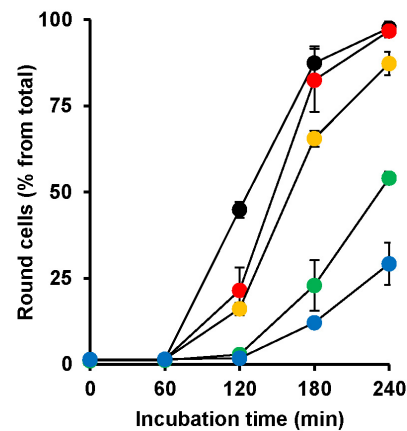

FIGURE 3 | Effect of U18666A on the TcdB-induced cell rounding of Vero cells. (A,C) Vero cells pretreated for $24 \mathrm{~h}$ with increasing concentrations of U18666A as indicated or without pretreatment (mock) were intoxicated with (A) $10 \mathrm{pM}$ or (C) $100 \mathrm{pM}$ TcdB. Representative images were taken microscopically after time point 0 min [upper row in $\mathbf{( A , C )}$ ] and 300 min [lower row in $\mathbf{( A )}$ ] or 240 min [lower row in (C)]. (B,D) Quantification of the TcdB-induced cell rounding over time in mock-treated (black filled circles) and $24 \mathrm{~h}$ U18666A-pretreated HeLa cells ( $1 \mu \mathrm{M}$, red filled circles; $2 \mu \mathrm{M}$, orange filled circles; $5 \mu \mathrm{M}$, green filled circles, $10 \mu \mathrm{M}$, blue filled circles). Graphs in (B,D) show mean percentage values of round cells as indicated by three parallel experiments performed in independent wells. Error bars represent $\pm \mathrm{SD}$. 
A

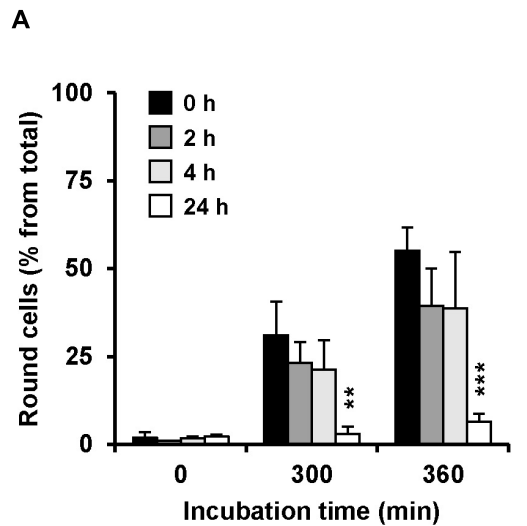

B

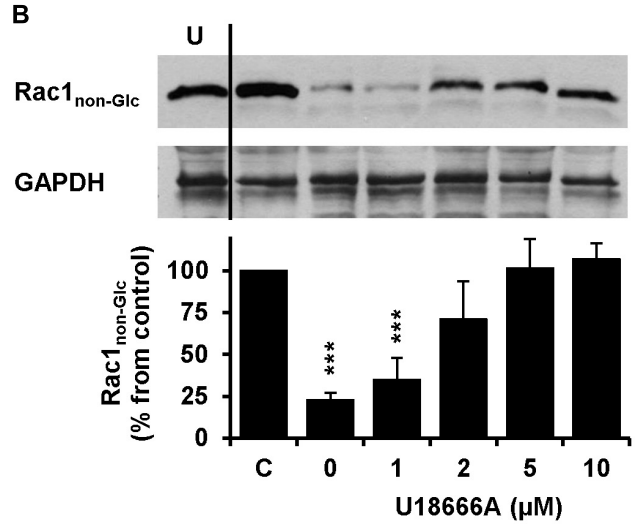

FIGURE 4 | Effect of U18666A on the TcdB-induced Rac1 glucosylation and role of U18666A pretreatment duration on TcdB-induced cell rounding in Vero cells. (A) Vero cells were preincubated for $0 \mathrm{~h}$ (black bars), $2 \mathrm{~h}$ (dark gray bars), $4 \mathrm{~h}$ (light gray bars), and $24 \mathrm{~h}$ (white bars) with the U18666A compound, prior to TcdB intoxication (10 pM) and microscopic analysis of TcdB-induced cell rounding over time. The mean percentage values of round cells at the indicated incubation times after addition of the toxin and from three parallel experiments performed in independent wells are plotted in the bar chart. Error bars represent \pm SD. Asterisks indicate statistical significance at each time point compared to control (black bar) with ${ }^{\star *} p<0.01$ and ${ }^{\star \star *} p<0.001$. (B) Immunoblots against non-glucosylated Rac1 (Rac1 $1_{\text {non-Glc }}$ ) and GAPDH (loading control) are shown (upper panel), obtained with whole-cell lysates that were generated from Vero cells pretreated for $24 \mathrm{~h}$ with increasing concentrations of U18666A as indicated and after intoxication for 120 min with 100 pM TcdB. In a control sample (C) cells were left without U18666A pretreatment and toxin addition. In another control $(\mathrm{U})$ cells were preincubated with $10 \mu \mathrm{M}$ U18666A but were left without toxin treatment. The bar chart (lower panel) shows the quantification of the Rac1 signals (normalized with the signals of the GAPDH loading control) relative to the control sample (C), which was set to $100 \%$. Error bars represent \pm SEM, calculated from six experiments performed in independent wells (three experiments in parallel on two different days). Asterisks indicate statistical significance at each time point compared to control (C) with ${ }^{\star \star \star} p<0.001$.

mock- and U18666A-pretreated Vero cells at time points zero and $300 \mathrm{~min}(10 \mathrm{pM} \mathrm{TcdB})$ and at time points zero and $240 \mathrm{~min}(100 \mathrm{pM})$, respectively, after toxin addition. Diagrams in Figures 3B,D show the corresponding quantification of TcdBinduced cell rounding over time for $10 \mathrm{pM}$ or $100 \mathrm{pM} \mathrm{TcdB}$, respectively. After $300 \mathrm{~min}$, cell rounding induced by $10 \mathrm{pM}$ TcdB was strongly reduced to $\sim 10 \%$ in Vero cells pretreated with 5 and $10 \mu \mathrm{M}$ U18666A vs. mock-pretreated cells ( $\sim 60 \%$ cell rounding) (Figure 3B). In cells intoxicated with $100 \mathrm{pM} \mathrm{TcdB}$, nearly $100 \%$ cell rounding was observed after $210 \mathrm{~min}$, which was decreased to $\sim 50 \%$ by pretreatment with $5 \mu \mathrm{M}$ U18666A and to $\sim 25 \%$ by pretreatment with $10 \mu \mathrm{M}$ U18666A. Thus, U18666A confers robust resistance in Vero cells toward $10 \mathrm{pM}$ TcdB and moderate resistance toward $100 \mathrm{pM}$ TcdB. Notably, the protective effect of U18666A against TcdB was more pronounced in Vero than in HeLa cells.

The influence of the pretreatment time of U18666A on the intoxication of Vero cells with TcdB was analyzed. To this end, Vero cells were pretreated with $10 \mu \mathrm{M} \mathrm{U18666A}$ for $0,2,4$, and $24 \mathrm{~h}$, prior to intoxication with $10 \mathrm{pM}$ TcdB. Eventually, TcdB-induced cell rounding was analyzed microscopically and quantified after 0, 300, and $360 \mathrm{~min}$. Importantly, $24 \mathrm{~h}$ pretreatment with the U18666A compound strongly inhibited TcdB-induced cell rounding (from $\sim 60 \%$ in mock-pretreated cells to $\sim 10 \%$ after $360 \mathrm{~min}$ of $\mathrm{TcdB}$ intoxication) (Figure $4 \mathrm{~A}$, black bar vs. white bar). Pretreatment with $10 \mu \mathrm{M}$ U18666A for 2 and $4 \mathrm{~h}$ did not reduce TcdB-induced cell rounding significantly after 300 and 360 min of intoxication, when compared to mockpretreated cells (Figure 4A, black bar vs. dark gray bar and black bar vs. light gray bar). Thus, also in Vero cells the incubation time has a major impact on the U18666A-mediated inhibition of
TcdB. Similarly as observed with HeLa cells, a short incubation of Vero cells with the U18666A compound inefficiently protects these cells against TcdB intoxication.

To confirm our findings with another experimental approach, we generated whole-cell lysates from Vero cells intoxicated for 120 min with 100 pM TcdB, followed by immunoblotting against the TcdB target protein Rac1 with an antibody that detects only the non-glucosylated form of Racl. Prior to TcdB intoxication the cells were pretreated for $24 \mathrm{~h}$ with increasing concentrations of U18666A $(0,1,2,5$, and $10 \mu \mathrm{M})$. Whole-cell lysates obtained from untreated cells were used as control for maximal nonglucosylated Rac1 signal in the immunoblot. As expected, the Rac1 signal in whole-cell lysates obtained from TcdB-intoxicated cells without U18666A pretreatment was decreased to 10-20\% from control (100\%) (Figure 4B). However, the Rac1 signal was present almost to the level of the control in TcdB-intoxicated cells pretreated either with 5 or $10 \mu \mathrm{M}$ U18666A. Lower U18666A concentrations ( 1 or $2 \mu \mathrm{M}$ ) protected cells less effectively toward TcdB intoxication, because the Racl signal was found to be reduced to $\sim 30 \%(1 \mu \mathrm{M}$ U18666A) and $\sim 70 \%$ ( $2 \mu \mathrm{M}$ U18666A), respectively, in these samples. Notably, pretreatment of cells with U18666A had no influence on the Rac1 expression level or on the binding by the glucosylation-sensitive anti-Racl antibody.

\section{U18666A Decreases the Sensitivity of Human Intestinal Epithelial CaCo-2 Cells Against TcdB}

Since $C$. difficile is a pathogen of the human intestine, it was relevant to test whether U18666A confers resistance toward $\mathrm{TcdB}$ intoxication in the medically and physiologically more 
A
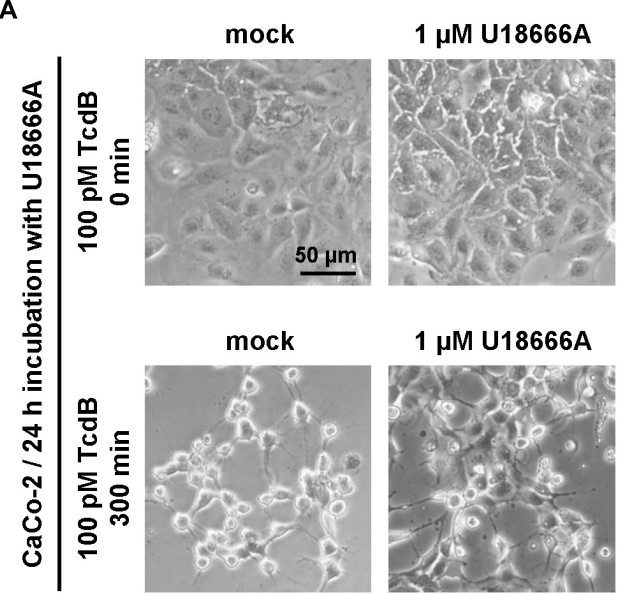

B

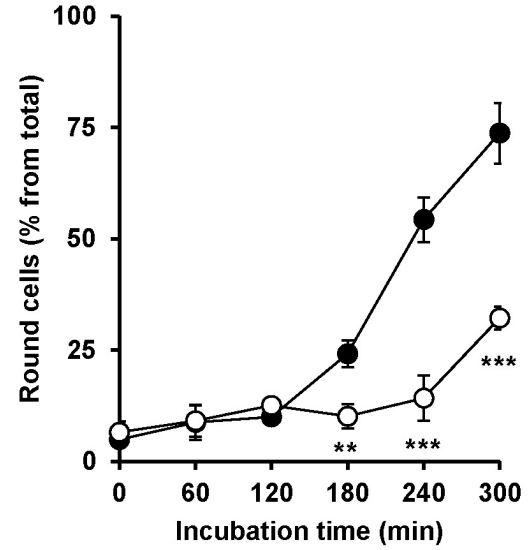

C
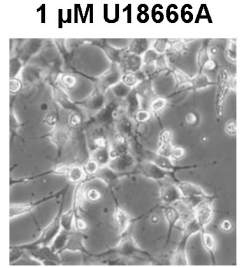

$2 \mu \mathrm{M} U 18666 \mathrm{~A}$

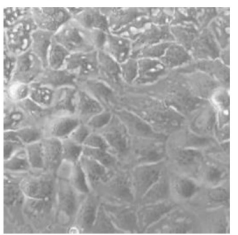

$2 \mu \mathrm{M}$ U18666A

$5 \mu \mathrm{M} U 18666 \mathrm{~A}$

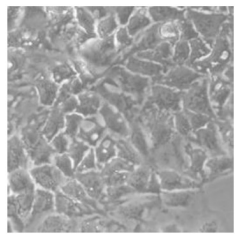

$5 \mu \mathrm{M}$ U18666A
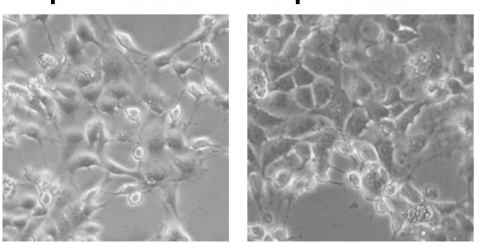

$10 \mu \mathrm{M} U 18666 \mathrm{~A}$

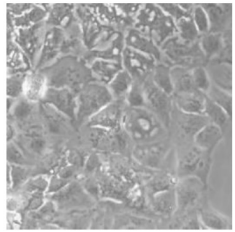

$10 \mu \mathrm{M} U 18666 \mathrm{~A}$

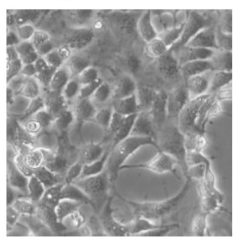

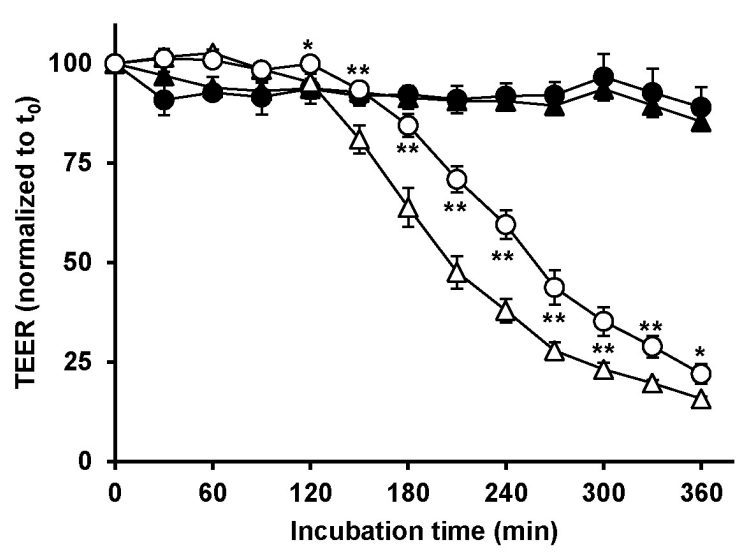

FIGURE 5 | Effect of U18666A on the intoxication of CaCo-2 cells by TcdB. (A) After pretreatment of CaCo-2 cells for $24 \mathrm{~h}$ with increasing concentrations of U18666A as indicated or without pretreatment (mock), cells were intoxicated with 100 pM TcdB for 300 min and cell morphology analyzed microscopically. Representative images after time point 0 min (upper row) and $300 \mathrm{~min}$ (lower row) are shown. (B) Quantification of the TcdB-induced cell rounding over time in mock-treated (black filled circles) and 24 h U18666A (10 $\mu$ M)-pretreated CaCo-2 cells (white filled circles). Graph shows mean values (percentage of round cells) from three parallel experiments performed in independent wells. Error bars represent \pm SD. Asterisks indicate statistical significance compared to control (mock-treated CaCo-2 cells) with ${ }^{* *} p<0.01$ and ${ }^{* * *} p<0.001$. (C) CaCo-2 cells grown in inserts were pretreated for $24 \mathrm{~h}$ with $10 \mu \mathrm{M}$ U18666A (circles) or were left without pretreatment (triangles), prior to apical addition of $100 \mathrm{pM} \mathrm{TcdB}$ (white filled circles and triangles) at time point 0 ( $\mathrm{t}_{0}$ ) and measurement of the transepithelial electrical resistance (TEER) at indicated incubation times. Parallel samples were not treated with TcdB (black filled circles and triangles). Diagram shows relative TEER values normalized to time point $0\left(t_{0}\right)$. Error bars represent $\pm S D$. Asterisks indicate statistical significance at each time point between white filled triangles $(-\mathrm{U} 18666 \mathrm{~A}+\mathrm{TcdB})$ and white filled circles $(+\mathrm{U} 18666 \mathrm{~A}+\mathrm{TcdB})$, with ${ }^{*} p<0.05$ and ${ }^{* *} p<0.01$.

relevant human colon carcinoma cell line $\mathrm{CaCo}-2$. To this end, CaCo- 2 cells were preincubated for $24 \mathrm{~h}$ with increasing concentrations of U18666A $(0,1,2,5$, and $20 \mu \mathrm{M})$, prior to addition of $100 \mathrm{pM} \mathrm{TcdB}$ and subsequent microscopic analysis of the cell morphology over time. Pretreatment of CaCo- 2 cells with increasing U18666A concentrations correlated with less microscopically observable cell rounding after incubation with TcdB for $300 \mathrm{~min}$, when compared to mock-pretreated cells (Figure 5A). The quantification of TcdB-induced cell rounding over time of mock- and $10 \mu \mathrm{M}$ U18666A-pretreated cells confirmed the protective effect of U18666A against TcdB also in CaCo-2 cells (Figure 5B). Pretreatment of CaCo-2 cells with 10 $\mu \mathrm{M}$ U18666A decreased TcdB-induced cell rounding to $\sim 25 \%$ after $300 \mathrm{~min}$ of intoxication.
To investigate the protective effect of U18666A on the intoxication of $\mathrm{CaCo}-2$ cells by $\mathrm{TcdB}$ by a further end point, the integrity of the barrier of function of $\mathrm{CaCo}-2$ cells, grown as polarized monolayers in hanging cell culture inserts, was analyzed in terms of the transepithelial electrical resistance (TEER). Accordingly, CaCo-2 cell monolayers were pretreated with $10 \mu \mathrm{M}$ U18666A for $24 \mathrm{~h}$ or were left untreated (mock) before apical addition of $100 \mathrm{pM}$ TcdB. Then, TEER was measured every $30 \mathrm{~min}$ over a period of $6 \mathrm{~h}$ after intoxication. In direct comparison, the TcdB-induced TEER decrease over time was delayed in U18666A-pretreated CaCo-2 cells when compared to mock-pretreated cells (Figure 5C). Thus, U18666A pretreatment reduced the $\mathrm{TcdB}$-induced disruption of the epithelial integrity of CaCo- 2 cells. 

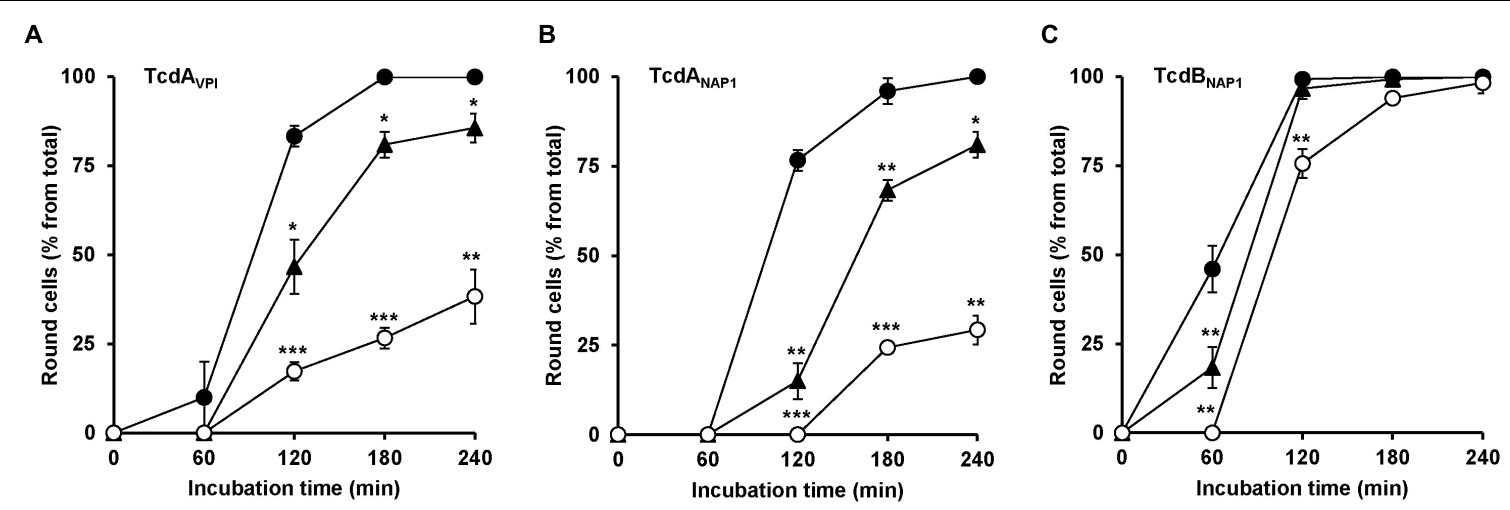

FIGURE 6 | Effect of U18666A on the intoxication of HeLa cells by TcdAVPI, TcdA $A_{N A P 1}$ and TcdBNAP1. HeLa cells preincubated with increasing concentrations of U18666A (0 $\mu \mathrm{M}$, black filled circles; $1.25 \mu \mathrm{M}$, black filled triangles and $10 \mu \mathrm{M}$, white filled circles) were intoxicated with (A) 10 pM VPI-derived TcdA (TcdAvPI), (B) 10 pM NAP1/027-derived TcdA (TcdA NAP1 $1_{1}$ or (C) 1 pM NAP1/027-derived TcdB (TcdBNAP1), prior to microscopic analysis of the cell morphology over time. Graphs in (A-C) show means (percentage values of round cells) from three experiments performed in parallel in independent wells. Error bars represent \pm SD. Asterisks indicate statistical significance compared to control (mock-treated HeLa cells) with ${ }^{*} p<0.05$, ${ }^{* *} p<0.01$, and ${ }^{* \star *} p<0.001$.

\section{U18666A Confers Protection Against VPI 10463-Derived TcdA and NAP1/027-Derived TcdA and TcdB}

Finally, it was tested whether U18666A also protects cells against TcdA from the historical C. difficile strain VPI 10463 and against TcdA and TcdB from the epidemic C. difficile strain NAP/027. For that purpose, HeLa cells were pretreated for $24 \mathrm{~h}$ with increasing concentrations of U18666A $(0,1.25$, and $10 \mu \mathrm{M})$, prior to addition of $10 \mathrm{pM}$ VPI-derived TcdA (TcdA $\left.A_{V I}\right), 10 \mathrm{pM}$ NAP1/027-derived TcdA (TcdA $A_{\text {NAP } 1}$ ) or $1 \mathrm{pM} \mathrm{NAP1/027-derived}$ TcdB $\left(\operatorname{TcdB}_{\mathrm{NAP} 1}\right)$. Subsequently, microscopic analysis of the cell morphology was performed. As summarized in Figure 6, a $24 \mathrm{~h}$ pretreatment of HeLa cells with $10 \mu \mathrm{M}$ U18666A effectively diminished cell rounding induced by $\mathrm{Tcd}_{\mathrm{VPI}}$ (Figure 6A), $\mathrm{Tcd}_{\mathrm{NAP} 1}$ (Figure 6B) or $\mathrm{TcdB}_{\mathrm{NAP} 1}$ (Figure 6C). It is of note, however, that the reduction of $\mathrm{TcdB}_{\mathrm{NAP} 1}$ intoxication by U18666A was less effective when compared to Tcd $A_{V P I}$ and $\mathrm{Tcd}_{\mathrm{NAP} 1}$, respectively, both of which were inhibited to an equal extent by the U18666A pretreatment.

\section{DISCUSSION}

The crucial role of membrane cholesterol for pore formation of TcdA and TcdB during their endocytic uptake into target cells was first described by the Aktories group in 2006 (Giesemann et al., 2006). Along with this finding, we found more recently that an active and functional SREBP-2 pathway, which plays a major role in cholesterol metabolism, is required in target cells for the cytotoxicity of $\operatorname{Tcd} A$ and $\operatorname{TcdB}$ and showed that the hypocholesterolemic drug simvastatin, which inhibits the HMG-CoA reductase, a key enzyme in cholesterol biosynthesis, efficiently protected cultured mammalian cells from $\mathrm{TcdB}$ intoxication (Papatheodorou et al., 2019). Since there is no structure of membrane-embedded $\mathrm{TcdA}$ or $\mathrm{TcdB}$, the exact interaction between membrane cholesterol and $\mathrm{Tcd} A / \mathrm{TcdB}$ is not known. However, a recently discovered "mirror code" controlling protein-cholesterol interactions in the outer and inner membrane leaflets (Fantini et al., 2016) seems to be present also within a region of TcdA and TcdB (amino acids 830-990) (Gerhard, 2017), which is in charge of pore formation (Genisyuerek et al., 2011). Cholesterol might be crucial for the insertion of the translocation domain of the toxins into the endosomal membrane. Otherwise, membrane cholesterol could serve as a platform for the correct positioning of transmembrane segments of the toxins within the endosomal membrane for generating a translocation-competent pore.

Prompted by the above mentioned observations that membrane cholesterol is crucial for the uptake of TcdA and TcdB in target cells, the U18666A compound came into our focus, since it has been described by several studies as potent inhibitor of cholesterol biosynthesis and/or intracellular trafficking (Cenedella, 2009). At least three membrane-bound enzymes in the cholesterol biosynthetic pathway, namely 2,3-oxidosqualene cyclase, desmosterol reductase and cholestenol delta-isomerase, are known to be inhibited by the U18666A compound (Duriatti et al., 1985; Bae and Paik, 1997; Moebius et al., 1998). The activity of HMG-CoA reductase, another key enzyme in cholesterol biosynthesis, is decreased by addition of low concentrations of U18666A, but increased at higher drug levels (Panini et al., 1984). Another feature of U18666A is the inhibition of the intracellular transport of cholesterol, namely from the lysosome to the endoplasmic reticulum (ER) and to the plasma membrane (PM), respectively, and from the PM to the ER (Liscum and Dahl, 1992; Underwood et al., 1998). Effects of U18666A on intracellular cholesterol trafficking are explained by its direct interference with the lysosomal membrane protein Niemann-Pick type C1 (NPC1), which transports cholesterol from receptor-mediated uptake of low-density lipoproteins (LDL) to post-lysosomal destinations (Carstea et al., 1997; Blanchette-Mackie, 2000; Lange et al., 2000; Lu et al., 2015).

The present study revealed that the U18666A compound confers increased protection to various mammalian cell lines 
against the C. difficile toxin TcdB. In addition, TcdA-inhibition by U18666A-pretreatment was confirmed in HeLa cells and TcdAinhibition by U18666A was more prominent when compared to $\mathrm{TcdB}$, irrespective of the source strain of both toxins. Inhibition of $\mathrm{TcdB}$ is more challenging most likely due to the fact that $\mathrm{TcdB}$ preparations are up to 1,000 -fold more toxic than TcdA preparations (Rothman et al., 1984). It is also feasible that TcdA membrane insertion and/or pore formation in endosomal membranes is more prone to changes of membrane cholesterol levels. Moreover, pretreatment with the U18666A compound was not equally protective against $\mathrm{TcdB}$ among the various tested cells. For instance, the inhibition of TcdBintoxication by U18666A pretreatment was more prominent in Vero cells when compared to HeLa cells at equal inhibitor concentrations. Possible explanations for this observation could be that either the compound is more efficiently taken up into Vero cells or that the compound is more efficiently degraded or excreted from HeLa cells by drug transporters. It is also feasible that membrane cholesterol levels and/or cholesterol uptake, intracellular transport and biosynthesis capabilities are vastly differing between HeLa and Vero cells, thus influencing the inhibitory potential of the U18666A compound in each cell line.

The replication of many viruses is associated with intact cholesterol biosynthesis and intracellular transport. Thus, it has been reported that U18666A suppress the replication of several viruses, such as ebola virus, dengue virus, human hepatitis $\mathrm{C}$ virus, and type I feline coronavirus (Poh et al., 2012; Lu et al., 2015; Elgner et al., 2016; Takano et al., 2017). The mechanism underlying the U18666A-mediated inhibition of TcdB and TcdA is likely related to a blockage of cholesterol biosynthetic enzymes and of the intracellular transport of endocytosed cholesterol from the culture medium to the plasma membrane and/or to endocytic vesicles. Consistent with this hypothesis, cells were strongly protected from toxin intoxication, when they were pretreated for at least $24 \mathrm{~h}$ with U18666A, but not after shorter incubation periods with the compound. We widely excluded the possibilities of (i) an inactivating effect of U18666A by direct binding to the toxins or (ii) through alteration of endosomal membranes through U18666A incorporation, because there was no efficient protection from $\mathrm{TcdB}$ after short incubation periods with U18666A, but protection when the U18666A-containing medium on top of cells was removed by replacement with TcdB-containing medium during the intoxication step.

The cholesterol-dependent pore formation by $\mathrm{Tcd} A$ or $\mathrm{TcdB}$ in endosomal membranes is a crucial step during cell entry of both toxins and this study corroborated that this specific step can be targeted by pharmacological tools such as U18666A. Importantly, U18666A also inhibited TcdA and TcdB variants from the epidemic NAP1/027 C. difficile strain. This finding indicates that cholesterol seems to be a conserved player in

\section{REFERENCES}

Aktories, K., and Just, I. (2005). Clostridial Rho-inhibiting protein toxins. Curr. Top. Microbiol. Immunol. 291, 113-145.
TcdA/TcdB intoxication. Thus, the development of cholesterollowering drugs, such as U18666A, as potential therapeutics against TcdA and TcdB might be of interest not only for the treatment of infections caused by non-epidemic C. difficile strains (such as VPI 10463), but also for the treatment of diseases associated with infections caused by the epidemic NAP1/027 C. difficile strain. However, the safety profile of U18666A for clinical use is not evaluated so far yet. Cataracts were described in rats that were treated daily with $10 \mathrm{mg} / \mathrm{kg} \mathrm{U} 18666 \mathrm{~A}$, but not when the rats were treated every fourth day with the U18666A compound (Cenedella and Bierkamper, 1979). Thus, the drug application form (enteral or rectal administration) and interval should be carefully considered in potential clinical studies on the efficacy and safety of U18666A and derivatives in the (supportive) treatment of severe CDI.

\section{DATA AVAILABILITY STATEMENT}

The raw data supporting the conclusions of this article will be made available by the authors, without undue reservation.

\section{AUTHOR CONTRIBUTIONS}

PP, SF, EC-O, and HB designed the research. PP, SK, AB-L, SF, $\mathrm{ED}, \mathrm{TT}, \mathrm{AW}$, and SS performed the research. PP, SK, AB-L, SF, KA, EC-O, CR, and HB analyzed the data. PP, KA, CR, and HB wrote the manuscript. All authors contributed to the article and approved the submitted version.

\section{FUNDING}

Research funding was received in the group of $\mathrm{HB}$ from the Deutsche Forschungsgemeinschaft (DFG; grant number Ba 2087/8-1, project no. 450938962) and in the group of EC-O and CR from the Vice-Presidency for Research of the University of Costa Rica (project no. B9450).

\section{ACKNOWLEDGMENTS}

We would like to thank Anna Anastasia, Monika Berther and Jana Kuhn for excellent technical assistance.

\section{SUPPLEMENTARY MATERIAL}

The Supplementary Material for this article can be found online at: https://www.frontiersin.org/articles/10.3389/fmicb. 2021.784856/full\#supplementary-material

Aktories, K., Schwan, C., and Jank, T. (2017). Clostridium difficile toxin biology. Annu. Rev. Microbiol. 71, 281-307.

Bae, S. H., and Paik, Y. K. (1997). Cholesterol biosynthesis from lanosterol: development of a novel assay method and characterization of rat liver 
microsomal lanosterol $\Delta$ 24-reductase. Biochem. J. 326, 609-616. doi: 10.1042/ bj3260609

Barth, H., Pfeifer, G., Hofmann, F., Maier, E., Benz, R., and Aktories, K. (2001). Low ph-induced formation of Ion channels by Clostridium difficile toxin B in target cells. J. Biol. Chem. 276, 10670-10676. doi: 10.1074/jbc.M009445200

Blanchette-Mackie, E. J. (2000). Intracellular cholesterol trafficking: role of the NPC1 protein. Biochim. Biophys. Acta Mol. Cell Biol. Lipids 1486, 171-183.

Carstea, E. D., Morris, J. A., Coleman, K. G., Loftus, S. K., Zhang, D., Cummings, C., et al. (1997). Niemann-Pick C1 disease gene: homology to mediators of cholesterol homeostasis. Science 277, 228-231. doi: 10.1126/science.277.53 23.228

Cenedella, R. J. (2009). Cholesterol synthesis inhibitor U18666A and the role of sterol metabolism and trafficking in numerous pathophysiological processes. Lipids 44, 477-487. doi: 10.1007/s11745-009-3305-7

Cenedella, R. J., and Bierkamper, G. G. (1979). Mechanism of cataract production by 3- $\beta$ (2-diethylaminoethoxy) androst-5-en-17-one hydrochloride, U18666A: an inhibitor of cholesterol biosynthesis. Exp. Eye Res. 28, 673-688. doi: 10.1016/ 0014-4835(79)90068-x

Chandrasekaran, R., and Lacy, D. B. (2017). The role of toxins in clostridium difficile infection. FEMS Microbiol. Rev. 41, 723-750. doi: 10.1093/FEMSRE/ FUX048

Duriatti, A., Bouvier-Nave, P., Benveniste, P., Schuber, F., Delprino, L., Balliano, G., et al. (1985). In vitro inhibition of animal and higher plants 2,3-oxidosqualenesterol cyclases by 2-aza-2,3-dihydrosqualene and derivatives, and by other ammonium-containing molecules. Biochem. Pharmacol. 34, 2765-2777. doi: 10.1016/0006-2952(85)90578-7

Egerer, M., Giesemann, T., Herrmann, C., and Aktorles, K. (2009). Autocatalytic processing of Clostridium difficile toxin B: binding of inositol hexakisphosphate. J. Biol. Chem. 284, 3389-3395. doi: 10.1074/JBC. M806002200

Elgner, F., Ren, H., Medvedev, R., Ploen, D., Himmelsbach, K., Boller, K., et al. (2016). The Intracellular cholesterol transport inhibitor U18666A inhibits the exosome-dependent release of mature Hepatitis C Virus. J. Virol. 90, 1118111196. doi: 10.1128/JVI.01053-16

Fantini, J., Di Scala, C., Evans, L. S., Williamson, P. T. F., and Barrantes, F. J. (2016). A mirror code for protein-cholesterol interactions in the two leaflets of biological membranes. Sci. Rep. 6:21907. doi: 10.1038/SREP21907

Genisyuerek, S., Papatheodorou, P., Guttenberg, G., Schubert, R., Benz, R., and Aktories, K. (2011). Structural determinants for membrane insertion, pore formation and translocation of Clostridium difficile toxin B. Mol. Microbiol. 79, 1643-1654. doi: 10.1111/J.1365-2958.2011.07549.X

Gerhard, R. (2017). Receptors and binding structures for clostridium difficile toxins A and B. Curr. Top. Microbiol. Immunol. 406, 79-96. doi: 10.1007/82_2016_17

Giesemann, T., Egerer, M., Jank, T., and Aktories, K. (2008). Processing of Clostridium difficile toxins. J. Med. Microbiol. 57, 690-696. doi: 10.1099/JMM. $0.47742-0$

Giesemann, T., Jank, T., Gerhard, R., Maier, E., Just, I., Benz, R., et al. (2006). Cholesterol-dependent pore formation of Clostridium difficile toxin A. J. Biol. Chem. 281, 10808-10815. doi: 10.1074/jbc.m512720200

Hall, A. (1994). Small GTP-binding proteins and the regulation of the actin cytoskeleton. Annu. Rev. Cell Biol. 10, 31-54. doi: 10.1146/annurev.cb.10. 110194.000335

Jank, T., and Aktories, K. (2008). Structure and mode of action of clostridial glucosylating toxins: the ABCD model. Trends Microbiol. 16, 222-229. doi: 10.1016/J.TIM.2008.01.011

Just, I., Selzer, J., Hofmann, F., and Aktories, K. (2008). "Clostridium difficile Toxin B as a Probe for Rho GTPases," in Bacterial Toxins - Tools in Cell Biology and Pharmacology, ed. K. Aktories (Weinheim: Chapman \& Hall), 159-168.

Just, I., Selzer, J., Wilm, M., Von Eichel-Streiber, C., Mann, M., and Aktories, K. (1995). Glucosylation of Rho proteins by Clostridium difficile toxin B. Nature 375, 500-503.

Kelly, C. P., and LaMont, J. T. (2008). Clostridium difficile - more difficult than ever. N. Engl. J. Med. 359, 1932-1940. doi: 10.1056/nejmra0707500

Lange, Y., Ye, J., Rigney, M., and Steck, T. (2000). Cholesterol movement in Niemann-Pick type C cells and in cells treated with amphiphiles. J. Biol. Chem. 275, 17468-17475. doi: 10.1074/jbc.M000875200
Liscum, L., and Dahl, N. K. (1992). Intracellular cholesterol transport. J. Lipid Res. 33, 1239-1254.

Lu, F., Liang, Q., Abi-Mosleh, L., Das, A., de Brabander, J. K., Goldstein, J. L., et al. (2015). Identification of NPC1 as the target of U18666A, an inhibitor of lysosomal cholesterol export and Ebola infection. Elife 4:e12177. doi: 10.7554/ eLife. 12177

Lyerly, D. M., Krivan, H. C., and Wilkins, T. D. (1988). Clostridium difficile: its disease and toxins. Clin. Microbiol. Rev. 1, 1-18. doi: 10.1128/cmr.1.1.1-18.1988

Moebius, F. F., Reiter, R. J., Bermoser, K., Glossmann, H., Cho, S. Y., and Paik, Y. K. (1998). Pharmacological analysis of sterol $\Delta 8=\Delta 7$ isomerase proteins with [3H]fenprodil. Mol. Pharmacol. 54, 591-598. doi: 10.1124/mol.54.3.591

Orrell, K. E., Zhang, Z., Sugiman-Marangos, S. N., and Melnyk, R. A. (2017). Clostridium difficile toxins A and B: receptors, pores, and translocation into cells. Crit. Rev. Biochem. Mol. Biol. 52, 461-473. doi: 10.1080/10409238.2017. 1325831

Panini, S. R., Sexton, R. C., and Rudney, H. (1984). Regulation of 3-hydroxy-3methylglutaryl coenzyme A reductase by oxysterol by-products of cholesterol biosynthesis. Possible mediators of low density lipoprotein action. J. Biol. Chem. 259, 7767-7771. doi: 10.1016/s0021-9258(17)42859-6

Papatheodorou, P., Barth, H., Minton, N., and Aktories, K. (2018). Cellular uptake and mode-of-action of Clostridium difficile toxins. Adv. Exp. Med. Biol. 1050, 77-96. doi: 10.1007/978-3-319-72799-8_6

Papatheodorou, P., Song, S., López-Ureña, D., Witte, A., Marques, F., Ost, G. S., et al. (2019). Cytotoxicity of Clostridium difficile toxins A and B requires an active and functional SREBP-2 pathway. FASEB J. 33, 4883-4892. doi: 10.1096/ fj.201801440R

Papatheodorou, P., Zamboglou, C., Genisyuerek, S., Guttenberg, G., and Aktories, K. (2010). Clostridial glucosylating toxins enter cells via clathrin-mediated endocytosis. PLoS One 5:e10673. doi: 10.1371/journal.pone.0010673

Poh, M. K., Shui, G., Xie, X., Shi, P. Y., Wenk, M. R., and Gu, F. (2012). U18666A, an intra-cellular cholesterol transport inhibitor, inhibits dengue virus entry and replication. Antiviral Res. 93, 191-198. doi: 10.1016/j.antiviral.2011.11.014

Pruitt, R. N., Chambers, M. G., Ng, K. K. S., Ohi, M. D., and Lacy, D. B. (2010). Structural organization of the functional domains of Clostridium difficile toxins A and B. Proc. Natl. Acad. Sci. U. S. A. 107, 13467-13472. doi: 10.1073/pnas. 1002199107

Rothman, S. W., Brown, J. E., Diecidue, A., and Foret, D. A. (1984). Differential cytotoxic effects of toxins A and B isolated from Clostridium difficile. Infect. Immun. 46, 324-331. doi: 10.1128/IAI.46.2.324-331.1984

Takano, T., Endoh, M., Fukatsu, H., Sakurada, H., Doki, T., and Hohdatsu, T. (2017). The cholesterol transport inhibitor U18666A inhibits type I feline coronavirus infection. Antiviral Res. 145, 96-102. doi: 10.1016/J.ANTIVIRAL. 2017.07.022

Underwood, K. W., Jacobs, N. L., Howley, A., and Liscum, L. (1998). Evidence for a cholesterol transport pathway from lysosomes to endoplasmic reticulum that is independent of the plasma membrane. J. Biol. Chem. 273, 4266-4274. doi: $10.1074 /$ jbc. 273.7 .4266

Conflict of Interest: The authors declare that the research was conducted in the absence of any commercial or financial relationships that could be construed as a potential conflict of interest.

Publisher's Note: All claims expressed in this article are solely those of the authors and do not necessarily represent those of their affiliated organizations, or those of the publisher, the editors and the reviewers. Any product that may be evaluated in this article, or claim that may be made by its manufacturer, is not guaranteed or endorsed by the publisher.

Copyright (C) 2021 Papatheodorou, Kindig, Badilla-Lobo, Fischer, Durgun, Thuraisingam, Witte, Song, Aktories, Chaves-Olarte, Rodríguez and Barth. This is an open-access article distributed under the terms of the Creative Commons Attribution License (CC BY). The use, distribution or reproduction in other forums is permitted, provided the original author(s) and the copyright owner(s) are credited and that the original publication in this journal is cited, in accordance with accepted academic practice. No use, distribution or reproduction is permitted which does not comply with these terms. 